\title{
Bilimsel Modellerin Sağlamlığı Üzerine
}

\section{On the Robustness of Scientific Models}

\author{
Ahmet Dinçer Çevik ${ }^{1}$ (D)
}

${ }^{1}$ (Arş. Gör. Dr.) Muğla Sıtkı Koçman Üniversitesi, Edebiyat Fakültesi, Felsefe Bölümü, Muğla Türkiye

ORCID: A.D.Ç. 0000-0001-5897-7381

Sorumlu yazar/Corresponding author: Ahmet Dinçer Çevik

Muğla Sıtkı Koçman Üniversitesi, Edebiyat Fakültesi, Felsefe Bölümü, Muğla Türkiye

E-mail/E-posta: dincercevik@mu.edu.tr

Başvuru/Submitted: 07.12.2021

Revizyon Talebi/Revision Requested:

21.12.2021

Son Revizyon/Last Revision Received:

22.12.2021

Kabul/Accepted: 26.12 .2021

Citation/Atıf: Cevik, Ahmet Dincer. "Bilimsel Modellerin Sağlamlığı Üzerine." Felsefe ArkiviArchives of Philosophy, 55 (2021): 49-65. https://doi.org/10.26650/arcp.1033984

\section{öz}

Sağlamlık analizi (robustness analysis), çok sayıda birbirinden bağımsız prosedür aracılığıyla aynı sonucun elde edilmeye çalışıldığı epistemik bir stratejidir. Söz konusu strateji bilim pratiğinde açıklama verme ve öndeyi türetiminde başvurulan modellerde sıklıkla kullanılır. Bilimsel modellerin ne derece sağlam ve hassas olduğunun belirlenmesi ile ilgili bir yöntem olduğu için sağlamlık analizi hem bilim insanları hem de bilim felsefecileri açısından epistemik bir öneme sahiptir. Bu makalede öncelikle, sağlamlık analizleri tarihsel çerçevede ele alınmaktadır. Ardından literatürde yer alan farklı sağlamlık analizi sınıflandırmaları ve sağlamlık analizlerinin işlevleri tartışılıp, modeller sağlamlık analizleri ve model temelli açıklamalar arasındaki ilişki ile ilgili bir ayrım yapılmaktadır. Bu ayrım modeller hakkında akıl yürütme ile modeller ile akıl yürütme arasındaki farklılıklar ile ilgilidir. Bu ayrıma göre bilimsel açıklamalarda kullanılan modellerin doğruluğunun koşullarının belirlenmesi sağlamlık analizleri olarak değerlendirilirken, modellerin uygulanabilirliği modeller ile akıl yürütme ile ilgilidir..

Anahtar Kelimeler: Sağlamlık analizleri, bilimsel modeller, de-idealizasyon, bilimsel açıklama, öndeyi

\section{ABSTRACT}

Robustness analysis is an epistemic strategy by which different and independent procedures are utilized to reach the same conclusion. Because this strategy is related with the robustness and sensitivity of the models, it has an epistemic importance for both scientists and philosophers of sciences. This paper, first, in a historical context, evaluates the robustness analysis. Then, the functions and the classifications of the robustness analyses are evaluated. Finally, a distinction is made with respect to robustness analysis. According to this distinction, the object of robustness tests is whether a given model that helps in explanation is true. Robustness analysis is about determination of the truth of the explanans, that is, determination of the truth conditions of the conditional part of the model. This is reasoning about models. However, applicability is not about whether the model is true but whether the antecedent of the model is satisfied in the case at hand. This is reasoning with models..

Keywords: Robustness, scientific models, de-idealization, scientific explanation, prediction 


\section{EXTENDED ABSTRACT}

Robustness analysis is an epistemic strategy by which different and independent procedures are utilized to reach the same conclusion. To explain the central idea behind the robustness analysis, French physicist Jean Baptiste Perrin's discovery of Avogadro's number is often cited. Perrin discovered the Avogadro number through thirteen independent ways. Because all of these methods have similar results, Perrin's result is hardly questioned by philosophers and scientists. The same method is currently being investigated in the context of scientific models as it is related with the degree of confidence in the model's results. Robust models are the target of the scientists. The more the model's result is stable toward different assumptions, the more it is reliable.

Because the strategy Perrin followed is related with the robustness and sensitivity of the models, it has an epistemic importance for both scientists and philosophers of sciences. In modelbased scientific practice, it is important to demonstrate that model result(s) are not related to one or more specific assumptions. Accordingly, in this paper, first, robustness analysis is briefly evaluated in a historical context. Discussions on the robustness analyses are frequently dated back to Richard Levins's article "The Strategy of Model Building in Population Biology." However, it is noteworthy that long before the modern discussions, philosophers such as Charles Sanders Pierce, William Whewell, and Alfred Ayer have referred to robustness analysis in indirect ways. This indicates that robustness analysis has different connotations. Further, the functions and the different classifications of the robustness analyses are examined. This examination reveals that although there are some differences between the different classifications of robustness types, they sometimes overlap in some certain points. Alternatively, the core of the discussions concerning the functions of the robustness analysis is about how and to what extent it is useful in connecting model-model and model-world relations.

Apparently, methodologists are suspicious about the virtues of robustness tests, and this is related with how to relate empiric work with a model's work. Here it is important to note that the literature shows that opinions are varied about the capabilities of robustness analysis. According to some critics, because robustness tests do not proceed with experimental ways, they cannot be used as a method of confirmation for the scientific models. Next, the differences between deidealization, which is another epistemic strategy, and robustness are elaborated and underlined. While de-idealization is known as a process of "concretization of a model" by replacing an assumption with a more realistic one, robustness analysis is not concerned with whether one assumption is more realistic than another; rather, it is concerned with the stability of the model under different assumptions. Both methods are especially important for the sciences that are more questionable in terms of their degree of exactness. However, conflating these methods would result in both conceptual and terminological problems. Finally, a distinction is made with respect to robustness analysis. This distinction is related with the applicability and truth conditions of the model. According to this distinction, the object of robustness tests is whether a given model that helps in explanation is true. Robustness analysis is about determination of the truth of the explanans, that is, determination of the truth conditions of the conditional part of the 
model. This is reasoning about models. However, applicability is not about whether the model is true but whether the antecedent of the model is satisfied in the case at hand. This is reasoning with models. 


\section{Giriş}

Bilim pratiğinde sağlamlık analizleri (robustness analysis) olarak bilinen metot, ekonomi, ekoloji, biyoloji, iklim bilimleri ve fizik gibi alanlarda farklı stratejilere referansla kullanılır. ${ }^{1}$

Sağlamlık analizlerinin arka planında yatan temel fikri açıklamak için genellikle Fransız Fizikçi Jean Baptiste Perrin’in (1870-1942) bir elementin bir molündeki atom sayısı ya da bir bileşiğin bir molündeki molekül sayısı olarak bilinen 'Avogadro sayısını' bulma öyküsü örnek olarak sunulur. ${ }^{2}$ Perrin, on üç farklı ve birbirinden bağımsız yöntem kullanarak Avogadro sayısına ulaşmıştır. ${ }^{3}$ Tüm bu yöntemler yaklaşık olarak aynı sonucu verdiği için Avogadro sayısının ölçümü ve atomların varlığı konusunda Perrin’in ölçümlerini önemli ölçüde teyit ettiği bilim insanları ve bilim felsefecileri tarafından kabul edilmiştir. ${ }^{4}$ Avogadro sayısının bulunmasında çok sayıda ve birbirinden bağımsız yöntem ve kanıt aynı sonuca işaret etmektedir. ${ }^{5}$ Sağlam bilimsel modeller bilim insanlarının hedeflerindendir, dolayısıyla farklı ve bağımsız araçlarla aynı sonuca

1 Sağlamlık analizlerinin farklı alanlardaki değerlendirilmelerine ilişkin iklim bilimleri için bkz; Wendy S. Parker, "When Climate Models Agree: The significance of Robust Model Predictions", Philosophy of Science, 78(4) (2011), 579-600, Zachary Pirtle, Ryan Meyer, Andrew Hamilton, "What Does it Mean When Climate Models Agree? A Case for Assessing Independence Among General Circulation Models", Environmental Science and Policy, 13, (2010) 351-361. Ekonometride bkz; Edward Emory Leamer ,"Let's Take the Con Out of Econometrics", American Economic Review, 73, 1, (1983), 31-43. Fizikte bkz. Koray Karaca, “Two Senses of Experimental Robustness: Result Robustness and Procedure Robustness", The British Journal for the Philosophy of Science, (2020), 1-29. Sağlamlık analizleri farklı alanlarda farklı anlamlarla kullanılabilmektedir. Örneğin istatistikte sağlam estimatörler uçdeğerler tarafından etkilenmeyenlerdir. Karmaşık sistemlerin incelenmesinde sağlamlık analizleri sonuç öndeyilerindeki parametrelerin seviyesindeki belirsizliğin etkisinin belirlenme metodudur. Bkz; Chiara Lisciandra, "Robustness Analysis and Tractability in Modeling”, European Journal for Philosophy of Science, Vol.7, Issue 1, (2017), 79-95.

2 Nancy Cartwright, "Replicability, Reproducibility and Robustness: Comments on Harry Collins", History of Political Economy 23, (1991), 143-155, Peter Achinstein, The Book of Evidence (Oxford: Oxford University Press, 2001), 243266, James Woodward, “Some Varieties of Robustness”, Journal of Economic Methodology, 13:2, (2006), 219-240, Bas C. van Fraassen, "The Perils of Perrin, in the Hands of Philosophers", Philosophical Studies, 143, (2009), 5-25, Alan F. Chalmers, "Drawing Philosophical Lessons from Perrin's Experiments on Brownian Motion: A Response to van Fraassen", The British Journal for the Philosophy of Science 62, ( 2011) , 711-732, Jutta Schickore-Kolodian Coko, "Using Multiple Means of Determination", International Studies in the Philosophy of Science, 27:3, (2013). 295-313, Klodian Coko, "Towards a Mutually Beneficial Integration of History and Philosophy of Science: The Case of Jean Perrin", The Past, Present, and Future of Integrated History and Philosophy of Science içinde, Eds. Emily Herring, Kevin Matthew Jones, Konstantin S. Kiprijanov, Laura M Sellers, (London: Routledge, 2019), 186-209, Klodian Coko, "Jean Perrin and the Philosophers' Stories: The Role of Multiple Determination in Determining Avogadro's Number”, Hopos: The Journal of the International Society for the History of Philosophy of Science, 10 (1), (2020), 143-193, Klodian Coko “The Multiple Dimensions of Multiple Determination”, Perspectives on Science, 28 (4), (2020), 505-541, Ian Hacking, Representing and Intervening: Introductory Topics in the Philosophy of Natural Science ( Cambridge: Cambridge University Press, 1983), 30, Wesley C. Salmon, Scientific Explanation and the Causal Structure of the World, (Princeton University Press, 1984), 215-217.

3 Klodian Coko, "Jean Perrin and the Philosophers' Stories: The Role of Multiple Determination in Determining Avogadro's Number", Hopos: The Journal of the International Society for the History of Philosophy of Science, 10 (1), (2020), 143-193

4 Ian Hacking, Representing and Intervening: Introductory Topics in the Philosophy of Natural Science (Cambridge: Cambridge University Press, 1983), 54-55, Wesley C. Salmon, Scientific Explanation and the Causal Structure of the World, (Princeton University Press, 1984),214-220.

5 Wesley Salmon bunu ortak neden ilkesinin uygulanması olarak değerlendirir. Bkz; Salmon, Scientific Explanation and the Causal Structure of the World, 221. 
ulaşabilme, ulaşılan sonuca olan güven derecesini yakından ilgilendirdiği için sağlamlık analizleri bilim pratiğinin önemli metotlarından birisidir.

Son yıllarda bilimsel açıklamaların doğası ile ilgili tartışmalar bilimsel yasaların statü ve işlevleri ile ilgili tartışmalardan ziyade büyük oranda bilimsel modellerin doğasına ve açıklamalardaki işlevlerine odaklanmıştır. Model temelli açıklamalar ile ilgili sorular, sağlamlık analizleri ile yakından ilgilidir. ${ }^{6}$ Model temelli açıklamalarda kullanılan soyutlama, idealizasyon türleri, kolaylaştırıcı varsayımlar sağlamlık testlerinin sınıflandırması ve işlevleri ile ilgili tartışmalarda önemli bir yer tutmaktadır. Çünkü sağlamlık analizleri ile modeller aracılığıyla türetilen sonucun modeldeki başka bir takım yanlış varsayımlara bağlı olmadığı gösterilmeye çalışılmaktadır. Bu anlamda, sağlamlık analizlerini bilim insanları için açıklama verirken ve öndeyide bulunurken başvurdukları modeller için 'kalite' testleri olma özelliğini taşımaktadır. Sağlamlık testlerinin ana fikri, model aracılığıyla ulaşılan sonuçların, modelde kullanılan önermelerin çeşitlendiği ve farklılaştığı durumda sabit kalıp kalmadığını analiz etmektir. Bu anlamda sağlamlık testleri, model aracılığıyla ulaştığımız çıkarımlara olan güvenimizin derecesini arttırmaktadır, çünkü bu testler yardımıyla bazı problemli model önermelerinin modellemede kullanılan diğer önermelerden bağımsız oldukları tespit edilebilmektedir. Sağlamlık testlerinin ne anlama geldiğini biçimsel olarak şu şekilde ifade etmek olanaklıdır: " $R$ sonucunun türetildiği, çekirdek bir $C$ varsayımı ve $A 1$ yardımcı varsayımını içeren bir $M$ modeli ile başlarız. Eğer $A 2, A 3, A 4$ vb. gibi farklı yardımcı varsayımlar altında aynı $R$ sonucu meydana geliyorsa, varsayımlardaki değişimin nihai sonucu etkilemediği sonucuna varırız"?

\section{Sağlamlık Analizlerinin Geçmişi ve Farklı Sağlamlık Analizi Sinıflandirmaları}

\subsection{Sağlamlık Analizlerinin Geçmişi}

Çok açık biçimde olmasa da farklı ve birbirinden bağımsız metotlarla aynı sonuca ulaşma meselesi Charles Sanders Pierce, William Whewell ve Alfred Ayer tarafından ele alınmıştır. Peirce felsefi metot hakkında şu noktanın altını çizer:

(...) felsefe yalnızca dikkatli bir analize tabii tutulabilecek gerçek önermelerden ilerlediği sürece ve her bu önermelerden hangi tek bir tanesinin kesin olmasından ziyade argümanlarının çokluğuna ve çeşitliliğine güvenmelidir metotlarında başarılı bilimleri taklit etmelidir. $^{8}$

6 Modeller genellikle incelenen süreç ya da mekanizmadaki davranışları betimleyen matematiksel denklem setlerinden oluşmaktadır. Bilimlerde farklı modeller kullanılmaktadır. Farklı modeller farklı işlevler görmektedir. Burada fenomenleri açıklama için postüle edilen matematiksel teorik modellere odaklanılmaktadır. Model kurmanın birinci adımı modellenecek ilgili bir hedef sistem tanımlamaktır. Açıklanacak sistem değişkenler ve bu değişkenler arasındaki ilişkiler yardımıyla tanımlanır. Dolayısıyla bir model temel olarak üç kısımdan oluşur: Değişkenler ve onların tanımları, bu değişkenlerle ilgili varsayımlar ve ('eğer... öyleyse' şeklindeki koşullu ifadeler) şeklindeki hipotezler.

7 Lisciandra, "Robustness Analysis and Tractability in Modeling", 85.

8 Charles Sanders Peirce, "Some Consequences of Four Incapacities", Journal of Speculative Philosophy, 2, (1868), 141. Aksi belirtilmedikçe çeviriler tarafima aittir. 
Ayer de tarihçinin geçmiş süreçlerle ilgili inanışının biçimlenişini ele alırken sağlamlık analizlerine açık olmayan bir şekilde referans verir:

(...) eğer bu kaynaklar sayıca çok ve birbirinden bağımsız ise, ve bunlar birbiri ile uzlaşı içinde ise, o [tarihçi], mesele ile ilgili verdiği hesap hakkında kendinden emin olacaktır. ${ }^{9}$

Whewell 'tümevarımın bilgi birlikteliği' (consilience of induction) kavramını açıklarken benzer şekilde şu noktanın altını çizer:

Bilgi birlikteliği, bir olgu kümesinden alınan tümevarımın farklı bir olgu kümesinden alınan tümevarım ile örtüştüğünde gerçekleşir. Bu bilgi birlikteliği tümevarımın içinde gerçekleştiği teorinin doğruluğu için bir testtir. ${ }^{10}$

Yukarıdaki alıntılar sağlamlık analizlerinin ana fikri olan farklı ve bağımsız araçlarla aynı ya da en azından büyük oranda benzer sonuçlara varma ile büyük oranda örtüşmektedir. Her üç alıntının ortak noktası farklı yollarla aynı ya da benzer sonuçlara ulaşmanın epistemolojik açıdan öneminin vurgulanmasıdır. Öte yandan Richard Levins'in "Popülasyon Biyolojisinde Model İnşası Stratejisi” makalesindeki model sonuçlarının sağlamlığının analiz edilmesi önerisi sağlamlık analizinin sistematik olarak ele alınmasının başlangıç noktası olarak ele alınır. ${ }^{11}$ Sağlamlık analizinin işlevleri ve statüsü ile ilgili tartışmaların izlerini Richard Levins’in meseleyi açık bir biçimde tartıştığı şu alıntıda görmek olanaklıdır:

Ancak, en esnek modeller bile yapay varsayımlar içermektedir. Her zaman sonucun bir modelin temelleri ya da basitleyici varsayımların ayrıntılarına bağlı olduğu ile ilgili bir şüphe bulunmaktadır... Bu nedenle aynı problemi her birinin farklı basitleştirmeler ama ortak bir biyolojik varsayım içerdiği birkaç alternatif model ile ele almayı deniyoruz. Öyleyse, farklı varsayımlarına rağmen bu modeller bizi benzer sonuçlara ulaştırıyorsa, modelin detaylarından görece olarak bağımsız, sağlam bir teoremimiz olduğunu söyleyebiliriz. Yani, bizim doğrumuz birbirinden bağımsız yalanların kesiştiği noktada bulunmaktadır. ${ }^{12}$ (vurgu eklenmiştir)

Levins, evrimsel biyolojideki çalışmalar bağlamında sağlamlık analizleri ile ilgili tespitler yapmaktadır. Levins bu alıntıda, yüksek derecede idealize edilmiş olan evrimsel modellerin verili bir data setinden ya da teorik modellerden farklı varsayımlarla benzer sonuçları verdiklerinde bu modeller aracılığı ile elde edilen sonucun sağlam olduğunun iddia edilebileceğini belirtmektedir. Bu yaklaşım, sağlamlık testlerinin epistemik bir destek sağladığını iddia edenlere göre farklı ve bağımsız yollar ile aynı sonuca ulaşabilmenin sonucun güvenilir olması ihtimalini arttırdığ 1 iddiası ile desteklenmektedir. Levins tek ve en iyi modeli seçmek yerine model sonuçlarının sağlamlığını

9 Alfred Ayer, The Problem of Knowledge, ( Macmillan, 1956), 38.

10 Larry Laudan, "William Whewell on the Consillience of Inductions", The Monist, 55(3), (1971), 369.

11 Richard Levins, "The Strategy of Model Building in Population Biology", American Scientist, 54(4), (1966), 421431.

12 Levins, "The Strategy of Model Building in Population Biology”, 423. 
analiz etmeyi önermektedir. Ona göre ele alınan fenomeni incelemek için birden fazla, tam olmayan, kusurlu model kullanılmalıdır. Levins modelleme pratiğinde kapsayıcılık, gerçekçilik ve kesinlik şeklinde sıralanan üç temel amaca aynı anda en yüksek düzeyde ulaşılamayacağını, bu nedenle de öndeyi ve açıklama pratiklerinde farklı modelleme stratejilerinin gözlemlenebildiğini belirtir. ${ }^{13}$

William Wimsatt, Levins'in çalışmalarını başlangıç noktası alarak kendi sağlamlık analizi anlayışını sunmaktadır. ${ }^{14}$ Wimsatt sağlamlık analizini "birden çok metot aracılığı ile hesaplama" (methods of multiple determination or triangulation) olarak tanımlar. ${ }^{15}$ Wimsatt bu ifade ile kullanılan farklı metotlar ile aynı sonuca yakınsamanın elde edilen sonucun doğruluğu için kanıt olarak değerlendirilmesini kastetmektedir. Ona göre sağlamlık analizlerinin bir takım ortak noktaları vardır:

(...) yanıltıcı olandan gerçek olanı, güvenilmez olandan güvenilebilir olanı, sübjektif olandan objektif olanı, perspektif açısından yapay olandan odaktaki objeyi ve daha genel olarak ontolojik ve epistemolojik olarak güvenilir ve değerli olanı güvenilmez, genellenemez, değersiz ve geçici olandan ayırma sağlamlık analizinde kullanılan varyantların ortak noktasıdır. ${ }^{16}$

Wimsatt'a göre sağlamlık analizi dört basamak ile karakterize edilir. Öncelikle, farklı ve bağımsız tanımlama ya da ölçüm süreçleri uygulanır ya da analiz edilir. Ardından bu süreçlerde değişmeden kalan özellikler belirlenir. Sonrasında bu değişmeden kalan özelliklerin hangi koşullar altında geçerli olduğu araştırılır. Son olarak, değişmeden kalan süreçlerin geçerliliğini sürdürmediği durumlar açıklanır.

Sağlamlık analizlerinin ortaya konulma biçimi ana hatlarıla, bilim felsefesinde 'mucizelere yer yok' (no miracle argument) olarak bilinen teze oldukça benzemektedir. Mucizelere yer yok argümanı, bilimsel gerçeklik tezini savunmak amacıyla ilk defa Hilary Putnam tarafından ortaya konmuştur. ${ }^{17} \mathrm{Bu}$ argümana göre eğer bilimsel teorilerin öndeyilerindeki başarısı en azından yaklaşık olarak doğru olmasaydı, bilimin öndeyilerindeki başarısı mucize olarak değerlendirilebilirdi. Jacob Stegenga da sağlamlık analizleri ile mucizelere yer yok argümanı arasındaki benzerliğin altını çizer. ${ }^{18}$ Öte yandan Anna Alexandrova ve Jay Odenbaugh sağlamlık analizleri ile mucizelere yer yok argümanının farkını şu sözlerle belirtir: "Sağlamlık analizleri olasılık $\operatorname{Pr}\left(O / M_{1} \& M_{2} \& \ldots \& M_{\mathrm{n}}\right)$ koşullu olasılığı ile ilgiliyken, mucizelere yer yok argümanı $\operatorname{Pr}\left(M / O_{1} \& O_{2} \& \ldots . . \& O_{\mathrm{n}}\right)$. koşullu olasıllı̆̆ ile ilgilidir. Burada $O_{\mathrm{i}}^{\prime}$ ler öndeyileri, $M_{\mathrm{i}}^{\prime}$ ler de modelleri (ya da teorileri) temsil eder" ${ }^{19}$

13 Levins, "The Strategy of Model Building in Population Biology, 421-431.

14 Wimsatt'ın sağlamlık analizleri ile ilgili görüşlerinin başka bir değerlendirmesi için bkz; Karaca, "Two Senses of Experimental Robustness: Result Robustness and Procedure Robustness", 1-2.

15 William C. Wimsatt, "Robustness, Reliability, and Overdetermination", Scientific Inquiry and the Social Sciences, Der. B. Brewer, B. E. Collins, 124-163, San Francisco, CA: Jossey-Bass, 1981.

16 Wimsatt, "Robustness, Reliability, and Overdetermination", 128.

17 Hilary Putnam "Mathematics, Matter and Method, Collected Papers, Vol. 2." (Cambridge: Cambridge University Press, 1975).

18 Jacob Stegenga "Robustness, Discordance, and Relevance", Philosophy of Science, 76 (5), (2009), 650-661.

19 Jay Odenbaugh-Anna Alexandrova, "Buyer beware: robustness analysis in economics and biology", Biology and Philosophy, 26 (5) (2011), 760. 
Öte yandan mucizelere yer yok argümanı ile sağlamlık analizleri arasındaki fark bu ikisinin amaçları açısından da ortaya konabilir. Putnam mucizelere yer yok argümanı ile bilimsel gerçekçiliği savunmak için bilimin işleyişine ilişkin daha genel bir iddiada bulunurken, sağlamlık analizleri, özellikle model temelli çalışma pratiğinin daha yoğun olduğu disiplin ile ilgili kapsamı daha dar argümanlar içerir. Sağlamlık analizlerinin birden fazla çeşidi bulunduğu için bilimsel gerçekliği savunma amacıyla ortaya sürülmüş olan Putnam’ın iddiasının farklı sağlamlık analizi çeşitleriyle nasıl bir ilişkisinin olduğu net değildir.

\section{Farklı Sağlamlık Analizi Sınıflandırmaları}

Model sağlamlığı analizleri farklı biçimlerde ortaya konur. ${ }^{20}$ Örneğin James Woodward'a göre sağlamlılığın her zaman sağlamlığın bir türü için öne sürülen argümanlar diğer sağlamlık türlerine uygulanabilir değildir. ${ }^{21}$ Çünkü sağlamlık tanımları, bilimsel araştırmalarda hangi rolü üstlendiklerine ve başarılı bir şekilde uygulanabilmeleri için hangi koşulları sağlamaları gerektiğine bağlı olarak değişmektedir. Örneğin Francesco Guala ve Andrea Salanti ekonomideki modellerin sağlamlığından bahsederken şunu belirtir: "Öncelikle farklı sağlamlık türleri arasında değiş tokuş yapılmalıdır; bir boyuttaki ilerleme (daha fazla sağlamlık) başka bir boyuttaki ilerlemeyi zorunlulukla garanti etmemektedir. İkinci olarak, sağlamlığı değerlendirme bilim insanının ilgisine ve pragmatik değerlendirmelerine son derece duyarlıdır...". 22 Guala ve Salanti'nin vurguladığı bu iki nokta Woodward'ın sağlamlık analizlerinin türleri ve kullanıldıkları bağlamlarla yakından ilişkili oldukları vurgusuyla tutarlıdır. Woodward, hedeflerine bağlı olarak dört farklı sağlamlık türü tanımlar. ${ }^{23}$ (1) Çıkarımsal să̆lamlık (inferential robustness) veriden varsayım uzayı boyunca elde edilen çıkarımsal ilişkileri öngörme ile ilgilidir. (2) Türetimsel sağlamlık (derivational robustness) farklı varsayımlar aracılı̆̆ıyla modelden teorik sonuçlar türetmeyle ilgilidir. Ölçüm sağlamlı̆̆ı (measurement robustness), deneysel alet grubu ile fiziksel entiteleri ölçme ile ilgilidir. Nedensel sağlamlık (causal robustness), müdahaleler altında bir genellemenin sabit olma durumunu ölçme ile ilgilidir. Öte yandan Guala ve Salanti üç tür sağlamlık tanımlamaktadır. ${ }^{24}$ (1) modelin idealizasyonlarındaki değişiklikler karşısında sağlamlık; (2) 'arka plan' koşullarındaki değişimler karşısında sağlamlık; (3) örtük nedensel mekanizmaya karşı sağlamlık. Michael Weisberg ve Kenneth Reisman ise sağlamlık ayrımlarını şöyle ortaya koyar: (1) parametre sağlamlı̆̆ı teorinin farklı parameter düzenlerinde korunması, (2) yapısal sağlamlık ise teoremin temsil çerçevesinden bağımsız olarak korunması ile ilgilidir. ${ }^{25}$

20 Örneğin Koray Karaca, fizikte deneysel prosedürler bağlamında "prosedür sağlamlığı” ("procedure robustness”) ve "sonuç sağlamlığı” ("result robustness”) tanımlar. Bkz. bkz; Karaca, "Two Senses of Experimental Robustness: Result Robustness and Procedure Robustness”, 7-8. Karaca prosedür sağlamlığını deneysel sürecin işlevinin deneyin sonuçlarındaki olası değişikliklere rağmen değişmeden kalabilmesi olarak tanımlar. Öte yandan Karaca’ya göre sonuç sağlamlığını klasik anlamıla farklı ve bağımsız metotlarla aynı sonuca ulaşılabilinmesidir. Prosedür sağlamlığı sonuç sağlamlığının ön koşuludur.

21 Woodward, "Some Varieties of Robustness", 219.

22 Francesco Guala-Andrea Salanti “On the Robustness of Economic Models”, Universita' Degli Studi Di Bergamo, (2002), 17.

23 Woodward, "Some Varieties of Robustness", 224, 231, 233, 235.

24 Francesco Guala-Andrea Salanti, "On the Robustness of Economic Models”, 5, 8, 11.

25 Michael Weisberg, M.-Kenneth Reisman, “The Robust Volterra Principle”, Philosophy of Science, 75(1), (2008), 115,120 . 
Öte yandan, Jani Raerinne'ye göre, hem Woodward'ın hem de Weisberg ile Reisman'ın sağlamlık analizi sınıflandırmaları "hassaslık analizlerini (sensitivity analysis) "sağlamlık analizlerinden" hem de "türetimsel sağlamlık analizini" (derivational robustness) "yeterli parametre sağlamlığından” (sufficient parameter robustness) ayıramaz. ${ }^{26}$ Raerinne’ye göre bu ayrımlar yalnızca kavramsal açıdan sorunlu değildir, aynı zamanda hassaslık analizleri ve sağlamlık analizleri farklı işlevlere sahip olduğu için anılan kavramların farklarını ortaya koymak önemlidir. ${ }^{27}$

Weisberg ve Reisman'ın sınıflandırmasında yer alan temsili ve yapısal sağlamlık analizleri benzer modellerdeki farklılaşmaları ya da bu modellerdeki belirli farklılıkların bu modeller ile varılan sonuçları nasıl etkileyeceğini araştırmayı hedefler. ${ }^{28}$ Raerinne’ye göre sağlamlık analizini modellerin yapısındaki ya da temsilindeki farklılaşmalar çerçevesinde tanımlamak ele alınan model setlerindeki modellerin sonuçlarının benzer olduğunu iddia etmeyi garanti edemez. Sonuç olarak Raerinne’ye göre, Weisberg ve Reisman'ın yapısal sağlamlık analizi sınıflandırmasınde "yapı" kavramı bu tür analizlerde ne tür değişmeler ya da farklılıklar ile ilgilendiğimiz konusunda bilgi veremediği için problemlidir. ${ }^{29}$

Raerinne'nin Weisberg ve Reisman'ın sınıflandırması ile ilgili ikinci eleştirisi ise bu sınıflandırmanın nedenler yerine etkilere odaklandığı için yetersiz oluşudur. Modeller yapılarında, temsillerinde farklılaşırlar çünkü farklı asli ve çözülebilirlik varsayımları içerirler. ${ }^{30}$ Farklı modelleme varsayımlarının modelin sonuçlarında yarattığı farklılıklar farklı sağlamlık analizi türlerini meydana getirir. Weisberg ve Reisman'ın sağlamlık analizi bu noktayı gözden kaçırdığı için farklı sağlamlık analizi türlerini ayırabilmek için kullanışlı değildir. ${ }^{31}$

Öte yandan Raerinne'ye göre Woodward'ın sağlamlık analizi sınıflandırması da problemlidir. Ona göre, Weisberg ve Reisman'ın sınıflandırması sağlamlık analizini dar, kısıtlı bir çerçevede ele alırken, Woodward bu terimi neden kullandığını açıklamaksızın kavramı neredeyse tüm empirik olmayan model araştırma yöntemlerini içerek şekilde ele alır. ${ }^{32}$ Raerinne'nin yorumuna göre, Woodward'ın çıkarımsal (“inferential”) sağlamlık analizi, Steven Orzack ve Elliot Sober’ın sağlamlık analizi tanımı ile uyuşmaktadır. Sober ve Orzack, Levins’in sağlamlık analizinin modelleri test ederken kullanılan empirik olmayan bir teyit yöntemi olarak nitelediği iddiasında bulunurlar. ${ }^{33}$ Levins bu eleştiriye yanıtında sağlamlık analizi ile bu çıkarımsal

26 Jani Raerinne, "Robustness and Sensitivity of Biological Models", Philosophical Studies, 166 (2), (2013), 293.

27 Jani Raerinne, "Robustness and Sensitivity of Biological Models", 293.

28 Model temelli açıklamalar ile sağlamlık analizleri arasındaki ilişkiyi "model aileleri” çerçevesinde ele alan yaklaşımlara örnek olarak bkz; Emrah N. Aydınonat, "The Diversity of Models as a Means to Better Explanations in Economics, Journal of Economic Methodology, 25:3, (2018), 237-251, Walter Veit, "Model Pluralism”, Philosophy of the Social Sciences. Vol. 50(2) 91-114. Vol. 75, No. 1, (2020), 664-677.

29 Jani Raerinne, "Robustness and Sensitivity of Biological Models", 293.

30 Farklı idealizasyon türleri için bkz; Ernan McMullin, "Galilean Idealization", Studies in History and Philosophy of Science 16, (1985) 247-273.

31 Jani Raerinne, "Robustness and Sensitivity of Biological Models", 293.

32 Jani Raerinne, "Robustness and Sensitivity of Biological Models", 293.

33 Steven Hecht Orzack-Elliot Sober "A Critical Assessment of Levins's the Strategy of Model Building in Population Biology”, The Quarterly Review of Biology, 68(4), (1993), 533-546. 
sağlamlığı kastetmediğini belirtir ve modellerin test ve teyit edilmesinin sağlamlık analizinden farklı ama onunla bağlantılı işlemler olduğunun altını çizer. ${ }^{34}$ Sonuç olarak Raerinne için, Woodward'ın çıkarımsal sağlamlığı ve Levins’in sözünü ettiği sağlamlık türleri farklıdır. Öte yandan, Woodward'ın ölçüm sağlamlığı analizi kısmen Wimsatt'ın sağlamlık analizi kavrayışına benzerdir. Woodward'ın nedensel sağlamlık kavramı, modellerin değişmezlik koşullarının boyutu ve çeşitliliği ile ilgilidir. Raerinne, Woodward'ın sağlamlık analizi ile modellerin araştırılması veya manipüle edilmesini aynı anlamda kullandığını iddia eder çünkü ona göre Woodward'ın nedensel sağlamlığı, modelin değişmezlik koşullarının araştırılması yöntemlerine bir örnek teşkil etmektedir. ${ }^{35}$ Son olarak, Raerinne, Woodward'ın türetimsel sağlamlığı kendisinin türetimsel sağlamlığına denk düştüğünü belirtir. ${ }^{36}$ Yine de, Raerinne’ye göre Woodward sağlamlık analizi ile hassaslık analizlerini karıştırmakta bu ikisinin ayrımı için bir kriter öne sürememektedir. Raerinne'ye göre Woodward'ın türetimsel sağlamlık için verdiği regresyon modeli örneğinde parametre değerinin modelin sonuçlarında ne gibi etkileri olduğunun araştırılması kendisinin hassaslık analizi kavramı ile yorumlanabilirdir. ${ }^{37}$

Raerinne, bu sınıflandırmaları değerlendirdikten sonra sağlamlık analizleri ile ilgili kendi ayrımını ortaya koyar ve öncelikle "hassaslık analizlerini" (sensitivity analysis) ele alır. Hassaslık analizleri, modelin parametre değerlerindeki farklılaşmalar ve değişikliklere neden olarak modelin başlangıç ve sınır koşulları ile bağlantısı çerçevesinde analiz edilmesidir. ${ }^{38}$ Raerinne’ye göre modellere iki şekilde müdahale edilebilir. ${ }^{39}$ 1) Modellenen ilişkinin ya da mekanizmanın değişkenlerinin değerlerine müdahale edilerek modelin dinamik doğası analiz edilir.) Parametre değerlerindeki değişmeleri sırasında da modellenen mekanizmanın ya da ilişkinin davranışını analiz etmek için de modellere müdahale edilebilir. İkinci türdeki müdahale model farklı arka plan koşulları değiştikçe, modellenen ilişki ya da mekanizmanın nasıl işleyeceğini göstermeye yarayan ve modelin istikrarının ya da arka plan koşullarının simülasyonu ya da araştırılmasıdır. ${ }^{40}$ Yani hassaslık analizleri, modelin başlangıç ve sınır koşulları değiştiğinde modelin sonuçlarının nasıl değiştiğinin analizidir.

Jaakko Kuorikoski, Aki Lehtinen and Caterina Marchionni ekonomik modelleme bağlamında sağlamlık analizleri ile ilgili bir ayrım yapar. ${ }^{41}$ Kuorikoski v.d., Wimsatt'ın "birden çok metot aracılığı ile hesaplama” olarak özetlenen türetimsel sağlamlık analizinin epistemik işlevini ekonomi disiplini bağlamında ele alarak bu alandaki modelleme pratiğinin en doğru biçimde "sistematik sağlamlık analizi" olarak değerlendirilebileceğini iddia eder. ${ }^{42}$ Kuorikoski

34 Richard Levins, "A Response to Orzack and Sober: Formal Analysis and the Fluidity of Science," Quarterly Review of Biology 68 (4), (1993).

35 Raerinne, "Robustness and Sensitivity of Biological Models", 294.

36 Raerinne, "Robustness and Sensitivity of Biological Models", 294.

37 Raerinne, "Robustness and Sensitivity of Biological Models", 294.

38 Raerinne, "Robustness and Sensitivity of Biological Models", 287.

39 Raerinne, "Robustness and Sensitivity of Biological Models", 287.

40 Raerinne, "Robustness and Sensitivity of Biological Models", 288.

41 Jaakko Kuorikoski, Aki Lehtinen, Caterina Marchionni, "Economic Modelling as Robustness Analysis", The British Hournal for The Philosophy of Science, 61(3), (2010), 541-567.

42 Kuorikoski v.d., "Economic Modelling as Robustness Analysis", 541. 
v.d. göre sağlamlık analizlerinin öndeyilerde başarısız olunsa bile bir teyit metodu olarak değerlendirilebilir. ${ }^{43}$ Kuorisoki v.d. bu iddialarını desteklemek için ekonomideki modellerde genellikle asli, Galileci ve çözülebilirlik varsayımları arasında bir ayrım yapar ve bu ayrım temelinde sağlamlık analizlerinin bir modeldeki aynı nedenin farklı matematiksel formülasyonlarını, yani çözülebilirlik varsayımlarının rollerini inceleme işlemi olduğunu ileri sürer. ${ }^{44}$ Kuorikoski vd. çözülebilirlik varsayımları ve sağlamlık analizi ile ilgili şunu belirtir:

(...) farklı modeller bazı varsayımları paylaşıtıları için bağımsız olmasalar da...

Şunu fark etmek önemlidir; modellerin birbirinden bağımsız olmasından ziyade benzer model seti içindeki tikel çözülebilirlik varsayımlarının bağımsızlı̆ğ, türetimsel sağlamlık analizi için kritik bir öneme sahiptir. ${ }^{45}$ (vurgu orijinaldir)

Burada Kuorikoski v.d. türetimsel sağlamlık analizi ile çözülebilirlik varsayımları ve ekonomi pratiği arasında bir ilişki kurmaktadır. Bu yaklaşıma göre, karar verme metotlarının problemli kısımları yani çözülebilirlik varsayımları birbirinden bağımsız olduğunda türetimsel sağlamlık analizi teorize etme işlemini hatalara karşı korur. Kuorikoski v.d. sağlamlık analizleri ile ilgili iddialarını ekonomide kullanılan metodolojiyi referans noktası alarak dile getirir. Onlara göre ekonomide, teorilerin sağlamlığını farklı modeller yardımıyla ve bu modellerde bulunan gerçekçi olmayan farklı varsayımlarla kanıtlama işi, hangi sonuçların ekonomik fenomen ile uyum içinde olduğunu, hangi sonuçların çözülebilirlik varsayımlarından kaynaklandığını, hangilerinin modelleyenden kaynaklı sonuçlar olduğunu belirlememize yardım eder. Bu şekilde türetimsel sağlamlık, empirik olarak teyit sağlamasa bile, modeller aracılığıyla varsayımlar farklılaşsa bile ulaşılan sonuçlara olan güvenin artmasına yardımcı olur. ${ }^{46}$

\section{Sağlamlık Analizleri ve De-idealizasyon}

Sağlamlık analizleri ile 'de-idealizasyon' farklı metotlardır. De-idealizasyon modeldeki belirli bir varsayımın daha gerçekçi başka bir varsayımla değiştirilmesidir. Bu anlamda de-idealizasyon 'modelin somutlaştırılması' olarak bilinir. Sağlamlık analizleri gibi, de-idealizasyon da epistemoloji ve bilim felsefesinde sıkça tartışılan konulardan birisi olduğu için sağlamlık analizinde olduğu gibi birçok başka soru ile beraber anılmaktadır. ${ }^{47}$ "Bu soruların bazıları de-idealizasyonun nasıl ilerlediği ya da araştırmanın amaçları ve doğasına göre hangi idealizasyon seviyesinin uygun olduğudur”. ${ }^{48}$ Öte yandan sağlamlık analizi farklı bir strateji izler. Bu metotta bir varsayımın diğerinden daha gerçekçi olup olmadığını önemsenmez; odaklanılan nokta incelenen fenomen ya da sürecin farklı varsayımlar çerçevesinde de değişmeden kalıp kalmadığıdır. Eğer bu sürecin sonunda ele alınan fenomen ya da sürecin sabit olduğu sonucuna varılabilirse, nihai olarak varılan sonucu sarsmaksızın modelin odaklandığı hedefin ayrıntıları göz ardı edilebilir. Bu anlamda

43 Kuorikoski v.d., "Economic Modelling as Robustness Analysis", 541.

44 Kuorikoski v.d., "Economic Modelling as Robustness Analysis”, 547, 548.

45 Kuorikoski v.d., "Economic Modelling as Robustness Analysis”, 559.

46 Kuorikoski v.d., "Economic Modelling as Robustness Analysis”, 563.

47 Lisciandra, "Robustness Analysis and Tractability in Modeling", 85.

48 Lisciandra, "Robustness Analysis and Tractability in Modeling", 85. 
sağlamlık analizi modeldeki "zararsız idealizasyonları" bulmak ile ilgilidir. ${ }^{49} \mathrm{Bu}$ süreç biyoloji, ekoloji, iklim bilimleri, meteoroloji ve ekonomi gibi analiz edilen sistemlerin biçimleniminin kesin olarak bilinemediği ya da belirlenemediği alanlarda çok büyük bir önem arz etmektedir. Bu alanlarda, genellikle birden fazla model ele alınan fenomenin araştırılmasında kullanılmaktadır. ${ }^{50}$

Weisberg ve Reisman yapısal sağlamlık (structural robustness) analizini şu şekilde tanımlar:

Bu tür sağlamlık analizinde, teorisyen farklı matematiksel yapılara sahip modeller ile modellenen sistemin nedensel yapısındaki değişiklikleri değerlendirir. Örneğin, biz modelimizde L-V [Lotka-Volterra] modeli ile başlayabiliriz, ancak avcı doygunluğu, avın saklanma yeteneği, avcının farklı besin kaynakları, hatta öğrenme gibi adaptasyon ile ilgili kompleks davranışları ile ilgili terimleri ekleyebiliriz. İlkece, herhangi bir ekolojik etkileşim modele eklenebilir. ${ }^{51}$

Weisberg ve Reisman yapısal sağlamlığı de-idealizasyon metoduna benzer biçimde ele almaktadır. Burada analiz farklı matematiksel yapılardaki farklı modelleri değerlendirerek ilerlemektedir. Örneğin, Lotka-Volterra (L-V) modelini analiz ederken Weisberg ve Reisman modelin yoğunluğa bağlı versiyonunu değerlendirip "Bu model L-V modelde önemli bir yapısal değişiklik yaratmaktadır, ancak çekirdekte yer alan eşleşmeleri bütün olarak tutmaktadır" ${ }^{52}$ "Bu daha gerçekçi modellerin adapte edildikçe sonucun geçerliliğinin artmasına güvenerek gerçekleşen durumdur" ${ }^{53}$

Sağlamlık analizleri ile de-idealizasyon stratejilerini karıştırmak terminolojik ve kavramsal açılardan karışıklıklara neden olacaktır: "terminolojik olarak, eğer sağlamlık analizleri deidealizasyonla eş anlamlı olarak ele alınırsa, Levins tararafından ortaya konan original tanım artık uygulanamaz hale gelir. Kavramsal açıdan iki kavramın çakışması, iki metodun iddia edilen teyit rollerinin farklı temellere dayandığı gerçeğini anlaşılmaz hale getirir" ${ }^{54}$

49 Mehmet Elgin ve Elliot Sober’a göre "Nedensel bir modelde idealizasyonların düzeltilmesi öndeyide bulunulan sonuç değişkeni değerinde çok fazla bir fark yaratmıyorsa bu idealizasyonlar zararsızdır. Zararsız idealizasyonlar açıklayıcı olabilir". Bkz; Mehmet Elgin-Elliot Sober "Cartwright on Explanation and Idealization", Erkenntnis 57, (2002), 448 .

50 Örneğin Michael Weisberg'in aktarımına göre "hava durumunu modellemek için Amerika Ulusal Hava Servisi global sirkülasyon örüntülerinin üç ayrı karmaşık modelini kullanmaktadır ve bu modellerin her biri havanın biçimlenmesi ile ilgili farklı idealizasyon varsayımları içermektedir." Bkz; Michael Weisberg, "Three Kinds of Idealization", Journal of Philosophy, 104 (12), (2007), 646.

51 Michael Weisberg-Kenneth Reisman, “The Robust Volterra Principle”, Philosophy of Science, 75(1), (2008), 11.

52 Weisberg-Reisman, "The Robust Volterra Principle”, 12.

53 Lisciandra, "Robustness Analysis and Tractability in Modeling", 86.

54 Lisciandra, "Robustness Analysis and Tractability in Modeling", 86. 


\section{Sağlamlık analizlerinin işlevleri}

Sağlamlık analizlerinin statüsü ve işlevleri ile ilgili iddialar farklılaşmaktadır. Sağlamlık analizlerinin teyit işlemindeki rolü sağlamlık analizlerinin epistemik işlevleri ile ilgili tartışmaların merkezindedir. Tartışmaların özü, sağlamlık analizlerinin model-model ve model-empirik dünya ilişkilerinin değerlendirilmesine rehberlik etmesi için uygun olup olmadığı ile ilgilidir. ${ }^{55}$ Bazı bilim felsefecileri sağlamlık analizlerinin ulaşılan sonuçların tesadüfi olmadığını gösterdiği iddiasına şüpheyle yaklaşmaktadır. Örneğin, Nancy Cartwright’a göre sağlamlık analizi "farklı uyarlamalar [örneğin modeller] farklı şeyler yaparak farklı enstrümanlar oluşturmaz, daha ziyade bunlar aynı şeyi yapmanın farklı yollarıdır. Bu farklı uyarlamalar birbirleriyle ilgisiz olmak bir yana, sıklıkla birbirlerine alternatif, hatta çelişki oluşturmaktadır. ${ }^{56}$ Cartwright'a göre tüm yanlış modellerin aynı sonucu ima etmesi aslında bir tesadüftür, ancak bu tesadüf sonucun doğruluğunu çıkarmamıza izin vermez. ${ }^{57}$ Bazı eleştirilere göre, sağlamlık testleri deneysel değil, $a$ priori akıl yürütmeye dayanmaktadır ve bu anlamda sağlamlık analizleri teyit metodu olarak iş göremezler. ${ }^{58} \mathrm{Bu}$ eleştirilerin odak noktası hipotez testlerinin empirik deneylerin referans alınarak yapılması gerektiği iddiasıdır. Örneğin, Steven Orzack ve Elliot Sober’e göre sağlamlık analizleri yalnızca temsil etmek için tasarlandıkları dünya hakkında değil, modelin kendi özelliklerinin araştırılması açısından kullanışlıdır. ${ }^{59}$ Benzer biçimde sağlam teoremlerin nedensel mekanizmaları belirleyemeyeceği ve modellerin bağımsız olmadığını iddia eden Jay Odenbaugh ve Anna Alexandrova için sağlamlık analizlerinin "teyit yerine keşif metodu olarak değerlendirilmesi daha isabetlidir" ${ }^{60}$ Öte yandan bilim pratiğine rehberlik etme açısından sağlamlık analizlerinin

55 Lisciandra, "Robustness Analysis and Tractability in Modeling", 82.

56 Nancy Cartwright, "Replicability, Reproducibility and Robustness: Comments on Harry Collins", History of Political Economy 23, (1991), 153.

57 Cartwright, "Replicability, Reproducibility and Robustness: Comments on Harry Collins", 154. Bilimsel modellerin 'yanlış’ olması, yanlış olma ile hangi koşulların göz önünde bulundurulduğu başlı başına bir tartışma konusudur. Bkz; Uskali Mäki "On a Paradox of Truth, or How not to Obscure the issue of Whether Explanatory Models Can be True". Journal of Economic Methodology, 20:3, (2013), 268-279, Daniel M. Hausman, "Paradox Postponed", Journal of Economic Methodology, 20:3, (2013), 250-254.

58 Nancy Cartwright, "Replicability, Reproducibility and Robustness: Comments on Harry Collins", History of Political Economy 23, (1991), Steven Hecht -Orzcak-Elliot Sober, "A Critical Assessment of Levins's the Strategy of Model Building in Population Biology", The Quarterly Review of Biology, 68(4), (1993), Robert Sugden, "Credible Worlds: The Status of Theoretical Models in Economics”. Journal of Economic Methodology 7 (1), (2000), 1-31, James Woodward, "Some Varieties of Robustness", Journal of Economic Methodology, 13:2, (2006), 219-240, Jacob Stegenga "Robustness, Discordance, and Relevance", Philosophy of Science, 76 (5), (2009), 650-661, Partick Forber, "Confirmation and Explaining How possible", Studies in History and Philosophy of Biological and Biomedical Sciences, 41, (2010), 32-40, Jay Odenbaugh-Anna Alexandrova, "Buyer beware: robustness analysis in economics and biology", Biology and Philosophy, 26 (5) (2011), 757-771, Wybo Houkes ve Krist Vaesen, "Robust! Handle with Care" Philosophy of Science, 57(5), (2012), 345-364, James Justus, "The Elusive Basis of Inferential Robustness", Philosophy of Science, Vol. 79, No. 5, (2012), 795-807.

59 Orzcak-Sober, "A Critical Assessment of Levins's the Strategy of Model Building in Population Biology", (1993).

60 Odenbaugh-Alexandrova, "Buyer beware: robustness analysis in economics and biology", 557. 
höristik işlevleri olduğunu iddia edenler bilim insanları ve bilim felsefecileri de vardır. ${ }^{61}$

Sağlamlık analizlerinin epistemik değerini savunanlar da eleştirenler de ayrıntılarda farklılaşmaktadır. Örneğin, Jaakko Kuorikoski v.d. sağlamlık analizlerinin “apaçık bir teyit prosedürü” değildir. Patrick Forber’a göre sağlamlık analizleri empirik testler başlamasına önsel olan muhtemel alternatiflerin oluşturduğu küme ile sınırlıdır. ${ }^{62}$ Öte yandan Michael Weisberg'e göre sağlamlık analizleri sağlam teoremleri teyit etmek için kullanışlı olmamakla beraber, 'düşük seviyeli teyit' ile beraber ele alındığında teyit için 'bir rol oynayabilir' ${ }^{63}$ İklim modellerini analiz eden Elisabeth Lloyd sağlamlık analizlerinin teyit derecesini arttırdığını iddia eder. ${ }^{64}$

\section{Explanansın Doğruluğu mu Explanandumun Temellendirilmesi mi?}

Sağlamlık analizi sınıflandırmalarının hemen hepsinde ortak olan nokta kendileri yardımıyla açıklamaya ve öndeyi türetiminde bulunulan modellerin doğru olup olmadığının analiz edilmesi sağlamlık analizlerinin konusudur. Sağlamlık analizleri explanansın doğruluğuna karar verme ile ilgilidir; burada modelin koşullu kısmının doğruluk koşullarının belirlenmeye çalışılır. Bu modeller hakkında akıl yürütme işlemidir. Öte yandan modellerin uygulanabilirliği modellerin doğru olup olmaması ile değil, modelin ön bileşeninin araştırılan mekanizma ya da süreç ile ilgili durumda sağlanıp sağlanmadığı ile ilgilidir. Bu modeller ile akıl yürütmedir. Bu ayrımı, yanıtları bu makalede verilemeyecek kadar geniş olan bazı sorular takip etmektedir. Bilimsel modeller gerçekten açıklama verirler mi sorusu en azından bazen onların gerçek açıklamalar verdiğinden emin olabilir miyiz sorusundan farklıdır. Hangi durumda modeller aracılığıyla gerçekten açıklama verebildiğimizi temellendirebiliriz sorusu tüm bilim pratiği için çözümü oldukça güç görünen bir sorudur. Soruyu biraz daha yumuşatıp, şimdiye kadar bilimsel modellerle en azından bazen gerçek açıklamalar verebildiğimize dair rasyonel kanıtlara sahip olup olmadığımızı sorduğumuzda ise bu soruya olumlu yanıt verebileceğimiz vaka çalışmalarını farklı disiplinleri incelenerek olumlu yanıt verilebileceğini görmekteyiz.

61 Richard Levins, "The Strategy of Model Building in Population Biology", American Scientist, 54(4), (1966), 421431, William C. Wimsatt, "Robustness, Reliability, and Overdetermination", Scientific Inquiry and the Social Sciences, Der. B. Brewer, B. E. Collins, 124-163, San Francisco, CA: Jossey-Bass, 1981, Jaakko Kuorikoski, ve Aki Lehtinen, "Incredible Worlds, Credible Results", Erkenntnis 70, (2009), 119-131, Jaakko Kuorikoski, Aki Lehtinen, Caterina Marchionni, "Economic Modelling as Robustness Analysis", The British Hournal for The Philosophy of Science, 61(3), (2010), 541-567, Micheal Weisberg, "Robustness Analysis.” Philosophy of Science 73, (2006), 730742, Michael Weisberg, M. ve Kenneth Reisman, "The Robust Volterra Principle”, Philosophy of Science, 75(1), (2008), 106-131, Elisabeth A. Lloyd, Varieties of Support and Confirmation of Climate Models. Aristotelian Society Supplementary Volume 83 (1), (2009), 213-232, Elisabeth A. Lloyd, Confirmation and Robustness of Climate Models. Philosophy of Science 77 (5), (2010), 971-984, Elisabeth A. Lloyd, Model Robustness as a Confirmatory Virtue: The Case of Climate Science. Studies in History and Philosophy of Science Part A 49, (2015), 58-68, Aki Lehtinen, "Derivational Robustness and Indirect Confirmation", Erkenntnis 83 (3), (2018). 539-576.

62 Patrick Forber "Confirmation and Explaining How possible", Studies in History and Philosophy of Biological and Biomedical Sciences, 41, (2010), 32-40.

63 Micheal Weisberg, "Robustness Analysis", Philosophy of Science 73, (2006), 730-742, Micheal Weisberg, Simulation and Similarity: Using Models To Understand the World, (New York: Oxford University Press, 2013), 167-169.

64 Elisabeth A. Lloyd, Varieties of Support and Confirmation of Climate Models. Aristotelian Society Supplementary Volume 83 (1), (2009), 213-232, Elisabeth A. Lloyd, Confirmation and Robustness of Climate Models. Philosophy of Science 77 (5), (2010), 971-984. 


\section{Sonuç}

Bilim pratiğinin genel bir analizi açıklamaların ve öndeyilerin çoğunlukla modeller aracılığıyla yapıldığını göstermektedir. Açılanacak ve hakkında sonuç üretilecek sistem ve süreçleri tam anlamıla yakalayan modellere rastlamak hayli zordur. Öte yandan modeller belirli idealizasyonlar temelinde oluşturulan bazı varsayımlar yardımıyla kurgulanmaktadır. Modellerin idealizasyonlar, bilinçli çarpıtmalar, soyutlamalar içermesi gerçek dünyadaki fenomenler hakkında nedensel bilgi veremeyecekleri anlamına gelmemektedir. Sözkonusu işlevleri yerine getiren yüksek derecede idealize edilmiş modellerin varsayımlarında, diğer modellerle ilişkilerinde ve ürettikleri sonuçlarda ne derece sağlam ve hassas oldukları sağlamlık analizleri ile ilgilidir. Sağlamlık analizleri modellerin işleyişinde gerçekçi olmayan varsayımların doğası ve statüsü hakkında her ne kadar bütüncül bir açıklama veremese de bu sağlamlık analizlerinin işlevi olmadığı anlamına gelmemektedir. Modelleme pratiği daha yakından incelendiğinde sağlamlık analizlerinin modeller hakkında analizler olduğu ve bu analizlerin potansiyel olarak farklı işlevleri barındırdığı görülebilmektedir.

\footnotetext{
Hakem Değerlendirmesi: Diş bağımsız.

Çıkar Çatışması: Yazar çıkar çatış,ması bildirmemiş,tir.

Finansal Destek: Yazar bu çalışma için finansal destek almadığını beyan etmiştir.

Peer-review: Externally peer-reviewed.

Conflict of Interest: The author has no conflict of interest to declare.

Grant Support: The author declared that this study has received no financial support.
}

\section{Kaynaklar / References}

Parker, Wendy S. "When Climate Models Agree: The significance of Robust Model Predictions." Philosophy of Science, 78(4) (2011): 579-600.

Pirtle, Zachary -Ryan Meyer Ryan -Hamilton Andrew. "What Does it Mean When Climate Models Agree? A Case for Assessing Independence Among General Circulation Models." Environmental Science and Policy, 13, (2010): 351-361.

Edward Emory Leamer."Let's Take the Con Out of Econometrics." American Economic Review, 73, 1, (1983): $31-43$.

Karaca, Koray. "Two Senses of Experimental Robustness: Result Robustness and Procedure Robustness." The British Journal for the Philosophy of Science, (2020), 1-29.

Lisciandra, Chiara. "Robustness Analysis and Tractability in Modeling." European Journal for Philosophy of Science, Vol.7, Issue 1, (2017): 79-95.

McMullin, Ernan. "Galilean Idealization." Studies in History and Philosophy of Science, 16, (1985): 247-273.

Carwright, Nancy. "Replicability, Reproducibility and Robustness: Comments on Harry Collins." History of Political Economy 23, (1991): 143-155.

Achinstein, Peter. The Book of Evidence. Oxford: Oxford University Press, 2001.

Woodward, James. “Some Varieties of Robustness." Journal of Economic Methodology, 13:2, (2006): 219-240.

van Fraassen, Bas C. "The Perils of Perrin, in the Hands of Philosophers." Philosophical Studies, 143, (2009): 5-25.

Chalmers, Alan F. "Drawing Philosophical Lessons from Perrin's Experiments on Brownian Motion: A Response to van Fraassen." The British Journal for the Philosophy of Science 62, ( 2011): 711-732 
Schickore, Jutta - Coko, Kolodian. "Using Multiple Means of Determination." International Studies in the Philosophy of Science, 27:3, (2013): 295-313.

Coko, Kolodian. "Towards a Mutually Beneficial Integration of History and Philosophy of Science: The Case of Jean Perrin". The Past,Present, and Future of Integrated History and Philosophy of Science. Eds. Emily Herring, Kevin Matthew Jones, Konstantin S. Kiprijanov, Laura M Sellers, 186-209. London: Routledge, 2019.

Coko, Klodian. “Jean Perrin and the Philosophers' Stories: The Role of Multiple Determination in Determining Avogadro's Number." Hopos: The Journal of the International Society for the History of Philosophy of Science, 10 (1), (2020): 143-193.

Coko, Klodian. “The Multiple Dimensions of Multiple Determination.” Perspectives on Science, 28 (4), (2020): 505-541.

Hacking, Ian. Representing and Intervening: Introductory Topics in the Philosophy of Natural Science. Cambridge: Cambridge University Press, 1983.

Salmon, Wesley C. Scientific Explanation and the Causal Structure of the World. Princeton University Press, 1984.

Peirce, Charles Sanders. "Some Consequences of Four Incapacities." Journal of Speculative Philosophy, 2, (1868): 140-157.

Ayer, Alfred. The Problem of Knowledge. Macmillan. 1956.

Laudan, Larry. "William Whewell on the Consillience of Inductions.” The Monist, 55(3), (1971), 368-391.

Levins, Richard. "The Strategy of Model Building in Population Biology." American Scientist, 54(4), (1966): 421-431.

Wimsatt, William C. "Robustness, Reliability, and Overdetermination." Scientific Inquiry and the Social Sciences. Eds. B. Brewer, B. E. Collins, 124-163, San Francisco, CA: Jossey-Bass, 1981.

Putnam, Hilary. Mathematics, Matter and Method, Collected Papers, Vol. 2. Cambridge: Cambridge University Press, 1975.

Stegenga, Jacob. “Robustness, Discordance, and Relevance.” Philosophy of Science, 76 (5), (2009): 650-661.

Odenbaugh, Jay - Alexandrova, Anna. "Buyer beware: robustness analysis in economics and biology." Biology and Philosophy, 26 (5) (2011): 757-771.

Guala, Francesco - Salanti, Andrea. “On the Robustness of Economic Models.” Universita' Degli Studi Di Bergamo, (2002):1-23.

Weisberg, Michael - Reisman, Kenneth. “The Robust Volterra Principle.” Philosophy of Science, 75(1), (2008): 106-131.

Raerinne, Jani. "Robustness and Sensitivity of Biological Models.” Philosophical Studies, 166 (2), (2013):285303.

Aydınonat, Emrah N. “The Diversity of Models as a Means to Better Explanations in Economics." Journal of Economic Methodology, 25:3, (2018): 237-251.

Veit, Walter: "Model Pluralism.” Philosophy of the Social Sciences. Vol. 50(2) 91-114. Vol. 75, No. 1, (2020): 664-677.

Orzack, Steven Hecht - Sober, Elliot. "A Critical Assessment of Levins's the Strategy of Model Building in Population Biology.” The Quarterly Review of Biology, 68(4), (1993): 533-546.

Levins, Richard. "A Response to Orzack and Sober: Formal Analysis and the Fluidity of Science." Quarterly Review of Biology 68 (4), (1993):547-555.

Kuorikoski, Jaakko - Lehtinen, Aki - Caterina Marchionni, Caterina. "Economic Modelling as Robustness Analysis”, The British Journal for The Philosophy of Science, 61(3), (2010): 541-567.

Cartwright, Nancy. "Replicability, Reproducibility and Robustness: Comments on Harry Collins", History of Political Economy 23, (1991), 143-155. 
Mäki, Uskali. "On a Paradox of Truth, or How not to Obscure the issue of Whether Explanatory Models Can be True." Journal of Economic Methodology, 20:3, (2013): 268-279.

Daniel M. Hausman, Daniel M. "Paradox Postponed." Journal of Economic Methodology, 20:3, (2013):250254.

Sugden, Robert. "Credible Worlds: The Status of Theoretical Models in Economics." Journal of Economic Methodology 7(1), (2000):1-31.

Woodward, James. "Some Varieties of Robustness." Journal of Economic Methodology, 13:2, (2006): 219-240.

Forber, Patrick. "Confirmation and Explaining How possible." Studies in History and Philosophy of Biological and Biomedical Sciences, 41, (2010): 32-40.

Houkes, Wybo - Vaesen, Krist. "Robust! Handle with Care." Philosophy of Science, 57(5), (2012):345-364.

Justus, James. "The Elusive Basis of Inferential Robustness." Philosophy of Science, Vol. 79, No. 5, (2012):795807.

Kuorikoski, Jaakko - Lehtinen, Aki. "Incredible Worlds, Credible Results", Erkenntnis 70, (2009:119-131.

Jaakko Kuorikoski - Aki Lehtinen - Caterina Marchionni, "Economic Modelling as Robustness Analysis", The British Journal for The Philosophy of Science, 61(3), (2010), 541-567.

Weisberg, Micheal . "Robustness Analysis." Philosophy of Science 73, (2006): 730-742,

Lloyd, Elisabeth A. "Varieties of Support and Confirmation of Climate Models." Aristotelian Society Supplementary Volume 83 (1), (2009): 213-232.

Lloyd, Elisabeth A. "Confirmation and Robustness of Climate Models." Philosophy of Science 77 (5), (2010): 971-984.

Lloyd, Elisabeth A. "Model Robustness as a Confirmatory Virtue: The Case of Climate Science." Studies in History and Philosophy of Science Part A 49, (2015): 58-68.

Lehtinen, Aki. "Derivational Robustness and Indirect Confirmation." Erkenntnis 83 (3), (2018): 539-576.

Elgin, Mehmet - Sober, Elliot. "Cartwright on Explanation and Idealization." Erkenntnis 57, (2002): 441450.

Weisberg, Michael. “Three Kinds of Idealization.”Journal of Philosophy, 104 (12), (2007): 639-659. 
